\title{
Flu Frames
}

\section{Abstract}

This article investigates how the frame concept was used in media studies of the 2009 flu pandemic representation. We examine how frame (or framing) analysis has illuminated sociological features of these depictions and how the frame concept facilitated an analytic understanding of the media representations. We first outline the principal uses of the concept in the social sciences. We then examine the approach and findings of empirical studies of the 2009 outbreak. We report our own findings under three headings: production; text; and consumption of flu frames. This schema provides a better understanding of key sociological dimensions of news responses to the 2009 pandemic. Most articles reviewed were conducted under the auspices of communication studies. We show that questions of frame production and the interpretation and challenging of frames, while not at the forefront of many analyses, nevertheless were not neglected.

\section{Introduction}

The H1N1 flu pandemic in the spring and summer of 2009 was a globally newsworthy story. In turn, the media attention stimulated social scientific interest about its characterization of the pandemic. According to health communication researchers, the manner in which the public were presented with information about pandemic flu was a key element in its management by nation-states and international health agencies. In many studies the 
investigation of the media characterization was cast as a question about how it was 'framed'. In this article we investigate how the frame concept was used in these studies. In this way we hope to derive a better understanding of the sociological dimensions of news responses to the 2009 pandemic. We conclude by reviewing some implications of the findings for models of moral panic (Cohen 1972) and epidemic psychology (Strong 1990).

\section{A brief history of a contested term}

In sociology, Goffman's (1974) formulation remains classic. For Goffman (1974: 9) frames are 'schemata of interpretation' that individuals apply to address the question, 'What is it that's going on here?'i Is the activity being witnessed a joke, a deception, a misunderstanding, a greeting, a theatrical performance, or what? Cognition, Goffman claims, owes more to such socially organized frames than is commonly thought. The way in which persons organize their activities is part of how we frame the world. Frames are 'organizational premises' that are 'sustained both in the mind and in activity' (Goffman 1974: 247).

As early as 1981, Goffman (1981: 67) dryly observed that plenty of researchers were using the frame concept with little mention of his writing on the subject. Goffman cited Tannen's (1979) survey, which showed that frame and cognate terms had become established in investigations carried out in anthropology, artificial intelligence, cognitive psychology, linguistics, social psychology and sociology. Often, there has been a tendency to conceptualize framing in more cognitive terms than Goffman proposed. Psychological ideas of 'script' and 
'schema' stood at odds with the concentration on communicative conduct emphasized by Goffman. However, both psychological and sociological conceptions were underpinned by the idea that frames offer 'structures of expectations' (Tannen 1979) that shape what we perceive in light of our prior experience and our acquaintance with how events and objects are organized. In psychology, the effect of frames on choices was demonstrated by Tversky and Kahneman's (1981) study where two equal scenarios, differently described as saving lives or causing deaths, attracted markedly different levels of support. Close affinities between Goffman's concept of frame and the concepts of 'schema' (Bartlett), 'habitus' (Bourdieu), 'perspective' (Shibutani) and 'thought style' (Fleck) were identified by Friedman (2011).

Of most direct relevance to our paper is the work of media sociologists, who were quick to appreciate the utility of the notion for analysing how media texts are produced and understood. Tuchman (1978:1) popularized the frame notion with her claim that 'News is a window on the world', noting that its content 'depends upon whether the window is large or small, has many panes or few, whether the glass is opaque or clear, whether the window faces a street or a backyard'. In one of the deftest definitions, Gitlin (1980: 6) suggested that frames were 'principles of selection, emphasis, and presentation composed of little tacit theories about what exists, what happens, and what matters'. This definition captured the textual dimension of framing. In everyday life, as Goffman noted, frames organize cognition and action. Media frames organize journalists' reports of the world and the understandings of those who rely on 
such reports. The critical task is to identify the frames that give order and pattern to news stories and to ask, why this frame and not another frame? Questions about how the news is framed have supplanted earlier concerns centring on the difficult notion of intentional bias (Schudson 2003: 35). The analytic terminology of frames allows a less charged way of examining representations of pandemic flu.

The discipline with the strongest current claim to 'own' the frame concept is communication studies. Entman (1993) boldly claimed that communications was the field that could broker the fractured understandings of the framing concept created by its multidisciplinary uptake. This influential article (cited nearly 3,500 times to date [Google Scholar, 7 May 2012]) proposed that the concept of framing consistently offers a way to describe the power of the communicating text' (Entman 1993: 51). Underpinning framing are the notions of selection and salience. Frames select aspects of reality and make them more salient. For Entman (1993:53) salience 'means making a piece of information more noticeable, meaningful or memorable to audiences'. Frames do at least four things: define problems, diagnose causes, make moral judgements, and suggest remedies. They may be present in different places within the communication process: in communicators, texts, receivers and the culture (Entman 1993: 52).

In previous studies of news framing, two sets of conceptual distinctions have proved especially significant. The first, by Iyengar (1991), distinguished 
episodic and thematic frames to indicate the differing characteristics of news coverage. Episodic frames focus on the specifics of the occurrence reported: the when, where and how of the event. Thematic frames place the occurrence in some wider context - the broader historical, social and economic background of the event. The second, by de Vreese (2005), distinguished issue-specific news frames (e.g. how the Intifada was framed, how an employment dispute was framed) from generic frames which were found recurrently across many issues and contexts, such as Iyengar's episodic/thematic distinction or Semetko and Valkenburg's (2000) five news frames ('conflict', 'human interest', 'attribution of responsibility', 'morality' and 'economic consequences'). These have proved valuable distinctions.

The attraction of the frame concept for those seeking to understand the news treatments of pandemic flu is clear. At moments of uncertainty and risk occasioned by the emergence of a new disease (Strong 1990), the frame concept pinpoints the little tacit theories about what exists, what happens, and what matters'. Following Gamson's (2001) suggestions (themselves echoing Hall's [1980] encoding/decoding model and subsequent developments in the sociology of culture) we classified the studies in light of three aspects of frame analysis:

(1) Framing the flu: How did experts and media professionals build and reproduce news flu frames? 
(2) Flu frames: What were the features of the frames through which the pandemic was represented in the news?

(3) Audiences and flu frames: how did audiences understand flu frames?

In seeking to determine how research studies used framing concepts to analyse media coverage of the 2009 pandemic, we initially conducted an electronic database and Google Scholar search for international published studies, using the search terms "pandemic flu" "swine flu" "framing" "H1N1" and "media framing. We selected a group of 15 studies published 2010-12. Table 1 summarises these in terms of (1) research problem (2) sources of data and methods of analysis and (3) framing conceptions employed. Our criteria were that the studies addressed aspects of media representation and included a focus on, or relevance to, the concepts of frames and framing.

\section{Framing the flu}

Kenneth Burke (1941: 4) noted the power of naming as a linguistic act: 'the mere act of naming an object or situation decrees that it is to be singled out as such-and-such rather than as something-other'. Vigso's (2010) article, 'Naming is framing', neatly puts this idea in sociological form. The contention is not new, however. In 1918 a New York Times editorial disputed the labelling of the flu pandemic as 'Spanish influenza' because it could not be proved that the disease was the same as the one that occurred many years earlier (Blakely 2003: 888). Vigso's (and Blakely's) point was that how the flu was initially framed stemmed from how it was named. The technical name, Influenza A 
(H1N1), was initially overshadowed by 'Mexican flu' and 'swine flu' in many countries. 'Naming controversies' were motivated by the interests of various national and international bodies in health and politics. The Mexican government rejected the name linking their country to the flu and sought to protect its trade and tourism interests by engaging in 'strategic reputation management'. The swine flu name played out in more complex ways - an Israeli government minister rejected the label because it meant that Jews would have to utter the name of an impure animal. The linking of a flu strain with pig keeping led China to place a ban on pork imports and to the Egyptian government ordering the slaughter of pigs (widely seen as a form of harassment of Egypt's Christian minority who kept them). In the USA and across the EU there was an immediate sensitivity to the threat to jobs and business interests. National and international agencies recognized that ' $\mathrm{H} 1 \mathrm{~N} 1$ ', difficult though it was to say, was preferable to the popular alternatives. Yet this proved hard to achieve. Vigso (2010) cites a study of Twitter messages in Sweden. Those originating from an official source of health information predominantly used H1N1 or a neutral variant; the messages from a national TV station overwhelmingly used the value-laden descriptor 'swine flu'. Our own search of UK papers found that, for popular and 'broadsheet' newspapers alike, 'swine flu' was the most favoured descriptor, featuring in 2,482 UK national newspaper headlines published between 27 April 2009 and 30 November 2009.

The selection of an appropriate name for the flu highlights cultural sensitivities as well as the play of social, economic and political interests at work among a 
range of stakeholders. In Greece and Cyprus, newspapers stuck closely to WHO advice with less than 5\% of articles using the name 'swine flu' (Doudaki 2011). However, in Malaysia 'swine flu' was frequently used in newspapers. It was felt that the dangers would be better understood if the Malay term for swine flu, selsema babi, was used (Ibrahim et al 2010), hence selsema babi and Influenza A (H1N1) were used interchangeably. These contextual variations remind us that naming the flu was not a once and forever event but subject to processes of contestation. Changes over time were noted by Chew and Eysenbach's (2010) investigation of Twitter messages. Between 1 May and 31 December 2009, use of the WHO recommended term, 'H1N1', increased from $8.8 \%$ to $40.5 \%$. The precise scope of this finding is difficult to ascertain. While the 'Twittersphere' is in theory global, estimates suggest that the profile of users is younger, better educated and better-off than most nation states' populations.

Naming is one manifest and initial dimension of the framing process. Other aspects of the production of news frames require investigation of the relationship of the published news item to its source. One way to address this is to observe or interview experts and media professionals. Only one study reviewed here took this approach. Holland et al. (2012) interviewed eight experts on infectious diseases who were frequently cited as sources for Australian newspapers and television in 2009. They found an element of dissension among the experts described as a 'framing contest', where a minority of experts interviewed felt that the others were 'toeing the party line', ignoring evidence that the pandemic was not as serious as government officials 
were convinced it was. Journalists commonly elicit differences among experts in order to make a 'balanced' story. In this case expert differences about the risks of swine flu did not become visible in news reports due to differential selfconceptions of the expert role and frustration with institutional constraints in playing the media game.

Another approach to the production of media frames is to consider the degree of concordance between the published news story and official press releases. Lopes et al (2012) found heavy dependence by Portuguese journalists on the information provided by the national health ministry. Coverage overlooked other potential information sources, such as nurses, specialist Internet sites, blogs and citizens as patients, resulting in a 'huge spiral of silence' (Lopes et al 2012: 23). Newspaper stories closely mirrored official sources because national health authorities, aware of the strategic importance of health communication, provided journalists with accessible packages of information that could readily be turned into news stories. Other studies (Holland and Blood 2010; Doudaki 2011; Duncan 2009) also indicated that, especially in the pandemic's early stages, there was extensive dependence on official sources of information and the frames they embodied.

A divergent picture of the framing process emerged in a Singapore study (Lee and Basnyat, 2012) which found that journalists, faced with covering the uncertain risks of pandemic flu, saw themselves as agents and advocates of wider public health interests. Journalists actively filtered the information 
provided by their official sources. But in addition the evolution from press release to news is marked by significant framing changes: expansion and diversification in dominant frames and emotion appeals, stronger thematic framing, more sources, conversion of loss into gain frames, and amplification of positive tone about the government's pandemic response efforts - suggesting that news stories are being framed to provide more than just "the facts"' (Lee and Basnyat 2012: 11).

The heavy dependence on official sources suggests that national health authorities successfully enacted WHO's (2004) Outbreak Communication Guidelines encouraging a strategy of early and active engagement with media organizations and staff. Yet the risk of journalistic dependency on expert sources makes critical analysis of the information provided more difficult (but not, as the Singapore study showed, impossible).

The contribution of these studies to an understanding of how the flu was framed shows (1) naming varies according to cultural context (2) lack of visibility of expert dissension in media reports (3) extensive dependence of news producers on official sources of information whose agenda could be simply reproduced (as in Portugal and Greece) or proactively expanded (Singapore) by the press.

\section{Flu frames}

The notion of the 'problem frame' suggests that news media operate with discourses assuming that 'danger and risk are a central feature of the effective 
environment' (Altheide1997:648). Chang's (2010) analysis of H1N1 pro-and anti-vaccination problem frames in five leading US newspapers' coverage identified 22 different frames used by advocates and opponents of vaccination. Tracking their shifting prominence in a nine-month period beginning April 2009, Chang found that pro-vaccine frames stressed protective factors while anti-vaccine frames expressed safety concerns. The greater prevalence and consistency of pro-vaccine frames across the period of the study led to these frames becoming dominant in newspaper coverage. However, the continuing prominence of the low availability of vaccine frame may have diluted the efforts of public health officials to get across their message that the vaccine would save lives.

Problem frames were not the only frames figuring in responses to pandemic flu. They were sometimes complemented by frames that emphasised government preparedness to deal appropriately with any of the risks confronting the nation, whether pandemic flu, terrorism or disaster (Stephenson and Jamieson 2009). In Portugal, especially at the start of the outbreak, newspapers adopted a dual framing, presenting an 'alarming scenario' abroad while emphasizing the 'serenity' and readiness of the Portuguese authorities' response at home (Lopes et al 2012: 24). This pattern was found elsewhere. Holland and Blood (2010) acknowledge the presence of risk and fear frames in initial Australian press coverage but suggest that the frames that quickly became dominant were 'government preparedness' and 'beyond containment'. In advance of the arrival of the virus, stories emphasised the plans that were in place to deal with the 
health crisis. Once cases started to appear in Australia, a 'beyond containment' frame became dominant. Press stories, to some extent mirroring WHO's own prediction, portrayed a rampant virus spreading at a rate that officials could not control. Reassuring stories ('just another flu') were subordinated to those that played up the public's fears ('experts warn of mutation').

Hilton and Hunt (2011) acknowledged the media's important role as a disseminator of scientific information about risk perception. They note that "perspectives or "frames" influence what are included or excluded from stories and can misrepresent the scientific evidence'. For example, in October 2009, when swine flu cases peaked a second time, newspaper interest decreased. The rating of articles and headlines separately as 'alarmist', 'reassuring' or 'neither' shows consistently high scores for 'neither' across the 12 month period of the study. Thus Hilton and Hunt conclude that in the UK there was little media 'over-hyping' of the swine flu pandemic. Reporting was largely measured and responsible.

Two studies of newspaper representations of the pandemic in Southeast Asia drew upon established frame analytic terminology. Ibrahim et al. (2010) adopted Semetko and Valkenburg's (2000) generic news frames in order to ascertain how they are configured in the context of Malaysian newspaper coverage of the pandemic. Here, the responsibility frame scored highest, followed by the morality, human interest, conflict, and economic consequences frames. In short, they found that all the newspapers wanted the government to 
take responsibility for solving the problems associated with the pandemic. Conversely, the economic consequences of the pandemic did not receive much attention in Malaysian news stories. Concerns with moral prescriptions, human interest and conflict between individuals, groups and institutions attracted moderate scores. Lee and Basnyat (2012) use Iyengar's distinction between episodic and thematic framing as one of their six coding categories. They found that journalists increase the proportion of thematic framing in their stories - they provide more context and background to the issues around the pandemic than was present in Ministry of Health press releases. Like Ibrahim et al., this study's use of established frame terms encourages comparisons between health communication news and other types of news.

The majority of studies examined representations in the print press. However, the Internet is fast becoming a favoured source of health information. Chew and Eysenbach (2010) presented a method for tracing collective sentiments and misinformation about the pandemic presented on Twitter but was not itself directly concerned with news reporting. Wang et al. (2010) investigated media frames in the reporting found in Google News, in the early stage of the pandemic between March and June 2009. The most frequent of the five frames identified in online news stories (see Table 1) was the 'transmission' and 'stigmatizing international students' frame. These two frames showed the greatest stability across the sample period. The latter frame indicated that international students continued to be stigmatized even when people came to know more about the sources of the disease. The 'individual prevention', 
'severity', and 'infected region' frames, on the other hand, were more prominent in stories in the earliest part of the sample period.

Oh et al. (2012) is the only study in our sample with an explicit comparative dimension. Of the seven frames (see Table 1) figuring in their analysis of the pandemic, the 'attribution of responsibility' frame was most frequent in US press reporting while the 'bare statistics' frame was most prominent in Korean coverage. This finding underlined the contrast in cultural belief between the activist US, where the belief was that the government had a responsibility to fight the epidemic, and Korea, where fatalistic views were more commonplace and thus news reporting concentrated on what is, on the statistics charting the course of the pandemic.

Fogarty et al (2011) examined Australian TV coverage. Despite swine flu's uncertain trajectory and TV's production culture that notoriously prizes 'seven second sound-bites' and simple, readily understandable information, reporting was found to be reassuring and non-alarmist. The study identified that the majority of reports were made by broadcast journalists, government representatives such as medical officers, and public health and infectious disease experts. Media reporting frames in this context consisted of 'updates and developments, mainly focussed on case increases' (Fogarty et al. 2011: 187). TV's framing of pandemic flu, at least in Australia, seemed more measured and less sensational than its press counterpart. 
While the studies reviewed indicate widespread recognition of the importance of frames and framing for understanding the news, systematic application of existing theoretical knowledge about news frames across this collection of studies was uneven. Several studies (Ibrahim et al. 2010; Lee and Basynat 2012; Oh et al. 2012; Wang et al. 2010) used or adapted existing conceptual distinctions. In some others (e.g. Chew and Eysenbach 2010; Fogarty et al; Hilton and Hunt 2011; Lopes et al. 2012) framing terminology was either marginal or could readily have been applied to strengthen the analysis presented. Further use of framing analysis would have enhanced the opportunities for comparison with other types of crisis news (cf. An and Gower 2009). Such comparative and generalizing ambitions depend to a degree on deductive theorizing (testing out existing frames) and are in tension with the aim of inductively-deriving frames in order to illuminate the particularities of pandemic framing in specific contexts (e.g. the approaches taken by Chang 2010; Holland and Blood 2010; Wang et al 2010 that were aimed at discovering new frames appropriate to their topic-matter). Of course, part of the attraction of the frame concept is its flexibility (Reese 2001) and tractability to a variety of explanatory endeavours. Perri 6 has argued (6 2005) that framing analyses are descriptive and not properly explanatory until they are anchored into some theoretical context (neo-Durkheimian institutional theory for 6 , attention cycles for Oh et al. 2012).

Our sample of studies tends to take the entire article as their unit of analysis. The varying significance of the constituent elements of articles was not always 
recognized by this approach. However, Doudaki attended to the front page placement of articles, Hilton and Hunt separately coded the headlines and the main body of reports, and Holland and Blood adopted an open-ended qualitative approach attentive to the framing power of headlines, lead paragraphs and quoted sources of information and opinion. Visual material was largely ignored. In our own investigation of 80 UK national newspaper front page stories, we found only 19 images, manifesting a limited visual repertoire. The most common image was a surgically masked face.

\section{Audiences and flu frames}

Many framing studies seem premised on the notion that the encoded news frame is so compelling, that audiences can only make a single sense of it. A contrasting view, derived from the encoding/decoding tradition of British cultural studies, contends that frames are a 'structured polysemy' - they can be read in various ways but these are 'structured in dominance'. There are both 'preferred readings' and negotiated or oppositional readings that may be made by members of different social groupings (Hall 1980). The sense that readers make of news frames cannot be simply assumed but becomes a matter of empirical examination.

If the chief source of information to laypersons about the pandemic is the mass media, how can media impact on laypersons' framing of H1N1 be specified? Wagner-Egger et al.'s (2011) interviews with French-speaking Swiss citizens in May and June 2009 identified key categories of collectivity. The 'heroes' of the 
unfolding drama are the experts, especially the researchers and the physicians who charted its course, prepared a vaccination and gave practical advice. The 'villains' were the media who stoked up people's fears and the big corporations, notably the pharmaceutical industry, which profited from the pandemic. The 'victims' were the poorer countries that lacked the resources to cope properly with their people's needs. Victims, however, were seen ambivalently. They were held culpable because of their lack of hygiene, discipline or 'culture'. This dramaturgical framing of heroes, villains and victims was 'at odds with the scientific way of framing disease threat, i.e., as an abstract risk. At least some of the misunderstandings of science attributed to laypersons may be due to these potentially incommensurable frames, rather than to deficits in understanding' (Wagner-Egger et al. 2010: 474-75).

The contested reception and interpretation of flu news frames is addressed by Nerlich and Koteyko's (2011) study of the UK swine flu outbreak. They emphasize the unique context of the 2009 outbreak. First, there were the repeated warnings of avian-type flu pandemic from 2004 onwards that did not materialize and encouraged scepticism towards claims about the risks of swine flu when it first appeared. Secondly, the use of digital technologies, especially social media such as Twitter and blogging, interacted with traditional news sources in the press and TV in the UK. Media commentary, especially in the early stages of the pandemic, focused not only on the nature of the flu threat ('biosecurity concerns') but also on how perception of these threats was 
changed by the impact of social media, an impact that was itself a topic of mass and social media discussion ('metacommunication').

Biosecurity concerns were reflected in UK media coverage during April and May 2009 , which repeated the pattern of previous outbreaks of infectious diseases. Initially alarmist reporting about the risks was followed by more measured and moderate accounts. What was new was the rise of metacommunicative reporting in which journalists and bloggers self-referentially reflected upon the role of their own reporting on the creation of the threats and risks posed by the pandemic. Print media discourses first blamed the officials (principally at WHO), then blamed the media ('scaremongering', 'crying wolf'), then shifted to a recognition of how 'we are hooked on hype' and ever willing to find new sources of panic. Meanwhile, the blogosphere identified the hype potential of pandemic flu weeks before the print media did. The discourses of both print and blogs concentrated on the dangers of 'panic fatigue' kicking in at just the point where actual flu cases transformed speculative risks into real ones. Nerlich and Koteyko show the complex interactions between social media and print journalism as both parties, in a situation of uncertainty about the flu's trajectory, attempt to decode dominant frames and offer a range of 'negotiated' or 'oppositional' framings. In a globalized world of mobilities and flows, where established boundaries become porous, it seems that new disease threats move rapidly from place to place. 
There are at least two areas of audience-oriented research into pandemic frames warranting further inquiry. One is to take some of the judgements made by coders of news reports and make them an issue for exploration by the readers of these reports (e.g. via interviews or focus groups). Several papers referred to versions of Ungar's (2008) distinction between alarming and reassuring discourses or frames. For example, Hilton and Hunt use this distinction in order to discover that over three quarters of UK coverage is 'neither', thus concluding that swine flu was not over-hyped. But from Goffman we might learn that an alarming/reassuring judgement is not simply a property of a text: it arises from the interaction of a reader and a text. Soliciting people's views is just as necessary as textual analysis. Secondly, text-based frame analyses need to take account of the various ways in which people read newspapers. Readers do not systematically read news articles from beginning to end. As readers pick up a newspaper and scan its contents, their attention is caught first by headlines and pictures. Singly and in conjunction, they direct the reader to newspaper stories of potential interest. Headlines and pictures are a potent source of first impressions that can play a significant role in shaping readers' attitudes towards the story's topic.

\section{Conclusion: Frames, moral panics, and epidemic psychologies}

Since most of the articles reviewed were conducted under the auspices of communication studies, our conjecture was that they would provide strong analyses of the content of frames but would be less convincing on the more 
sociological territory of production and consumption of texts. This proved to be only partially true. While questions of frame production on the one hand, and the interpretation and challenging of frames on the other, were not at the forefront of many analyses, they were not neglected.

Sociologists cannot help but notice the raised social anxieties provoked by the onset of an epidemic. When those anxieties are presented through colourful and exaggerated press reports, sociologists typically suspect the presence of media amplification and moral panic (Cohen 1973). Moral panic theory helps to specify a sociological interest in epidemics as matters of representation. However, the major difficulty with straightforwardly applying the theory is the difficulty in identifying a single, epidemic-specific folk devil around which the moral panic can be mobilized. It is possible to identify 'heroes, villains and victims' (Wagner-Egger et al. 2011) that indicate the pervasive moralization of the perception of swine flu. The occupants of these categories vary over time and place (big pharma for the Swiss, Mexicans and travellers for Americans). Also, in the case of emerging infectious diseases such as $H 1 N 1$, there was not the scope for exaggerated claims, since, in face of uncertainty, the wide support for medical expertise provides the default. Nevertheless, moral panic theory draws attention to the ways in which mediatized representations help to shape the public's conception of the nature of problems such as epidemics. Sociological interest is thus directed towards the characteristics of response to epidemics, not simply as threats to people's health or to the economy, but to the social order itself. 
This is the point of departure for PM Strong's (1990) model of 'epidemic psychology'. Strong identified elements of the 'distinctive collective psychology' that accompanied outbreaks of epidemic diseases. He proposed three psychosocial epidemics that run alongside the embodied kinds: an epidemic of fear, suspicion and stigmatization; an epidemic of interpretation, explanation and moralization; and an epidemic of proposals and action. Just as all members of a society are vulnerable to an epidemic in their midst, so too are all members of society vulnerable to the fears and open to the explanations and calls for action that an epidemic unleashes. Based on studies of medieval plagues and the AIDS scares of the 1980s, Strong's model was designed to identify the kinds of responses that might accompany any particular outbreak of an epidemic. It offered an ideal type of what occurs in the wild when the scope and risks of a novel disease are not yet determined. As we indicated, the initially alarmist print news frames did occur in several countries. Much national and international planning was premised on the possibility of an apocalyptic event of 1918 proportions. The short-lived alarmist framing is in accord with Strong's epidemic of fear. As our discussion of framing the flu demonstrated, health authorities sought to control the epidemics of fear and explanation through their association with medical expertise and their monopoly control of remedial actions to combat spread of the disease. When framing contests emerged, around vaccination or expert opinion, the home side won. The metacommunicative (Nerlich and Koteyko 2011) framing of the media's role in the epidemic of fear as a 'media pandemic' has interesting implications for 
Strong's model. The new media technologies compress Strong's three psychosocial epidemics, reducing their temporal phasing and complicating the communicative processes between the public, the media and experts. These are some of the ways that the study of flu frames presents an alternative and interesting way to uncover the specific forms of epidemic psychologies in different social and cultural contexts.

\footnotetext{
${ }^{\mathrm{i}}$ Goffman (1974: 9) italicizes 'it' in recognition of how the question, as stated, assumes a single answer. Goffman (1974:21) also acknowledges that more than one frame may be operating simultaneously.
}

\section{References}

Altheide, D.L. (1997) 'The news media, the problem frame and the production of fear'. The Sociological Quarterly, 38, 4: 647-668.

Blakely, D. (2003) Social construction of three influenza pandemics in the New York Times. Journalism \& Mass Communication Quarterly, 80: 884.

Burke, K. (1941) The Philosophy of Literary Form: Studies in Symbolic Action. Baton Rouge, LA: Louisiana State.

Chang, J. (2010) How U.S. Newspapers Frame the 2009 H1N1 Vaccine. http://nature.berkeley.edu/classes/es 196/projects/2010final/ChangJ_2010.p $\underline{\mathrm{df}}$

Chew, C. and Eysenbach, G. (2010) Pandemics in the age of Twitter: Content analysis of tweets during the 2009 H1N1 outbreak. PLOS ONE 5(11): e14118. doi:10.1371/journal.pone.0014118. 
Cohen, S. (1973[orig. 1972]) Folk Devils and Moral Panics. London: Paladin.

Doudaki, V. (2011) Representations of Disease and Threat: The Case of Swine Flu in Greece and in Cyprus. In Lee Baxter and Paula Braescu (eds), Fear within Melting Boundaries. Oxford: Inter-Disciplinary Press, 191-201.

Duncan, B. (2009) How the media reported the first days of the pandemic (H1N1) reported the first days of the pandemic: (H1N1) 2009: results of a EU wide media analysis. Eurosurveillance 14: 30.

Entman, R. M. (1993) 'Framing: Toward Clarification of a Fractured Paradigm'. Journal of Communication, 43, 4: 51-58.

Friedman, A. (2011) 'Toward a sociology of perception: Sight, sex, and gender', Cultural Sociology, 5: 187-206.

Fogarty, A.S., Holland, K., Imison, M. R., Blood, R., Chapman, S. and Holding, S. (2011) Communicating uncertainty - how Australian television reported H1N1 risk in 2009: a content analysis. BMC Public Health, http://www.ncbi.nlm.nih.gov/pmc/articles/PMC3079644/

Gamson, W. (2001) 'Foreword', pp. ix-xi in Stephen D. Reese et al (eds). (2001). Framing Public Life: Perspectives on Media and Our Understanding of the Social World. London and New York: Taylor \& Francis.

Gitlin, T. (1980) The Whole World is Watching. Berkeley: University of California Press.

Goffman, E. (1974) Frame Analysis: An Essay on the Organization of Experience. New York: Harper. 
Goffman, E. (1981) A reply to Denzin and Keller. Contemporary Sociology 10, 1: $60-68$.

Hall, S. ([1973] 1980) 'Encoding/decoding'. In S. Hall, D. Hobson, A. Lowe and P. Willis (Eds) Culture, Media, Language: Working Papers in Cultural Studies, 1972-79. London: Hutchinson: 128-38.

Hilton, S. and Hunt, K. (2011) UK newspapers' representations of the 2009-10 outbreak of swine flu: One health scare not over-hyped by the media? Journal of Epidemiological Community Health 65, 941-946.

Holland, K., Blood, R., Imison, M., Chapman, S. and Fogarty, A. (2012) Risk, expert uncertainty, and Australian news media: public and private faces of expert opinion during the 2009 swine flu pandemic, Journal of Risk Research, 15, 6: 1-15.

Holland, K. and Blood, R.W. (2010) Not just another flu? The framing of swine flu in the Australian Press. In Media, democracy and change: Refereed proceedings of the Australian and New Zealand Communications Association annual conference, Canberra July 7-9, ed. K. McCallum. http://www.anzca.net/conferences/anzca10-conference.html.

Ibrahim, F., Normah, M. and Peng Kee, C. Framing a pandemic: Analysis of Malaysian mainstream newspapers in the H1N1 coverage. Paper presented at International Communication Association 2010 Preconference - Health 
Communication Campaigns: Issues and Strategies in Asia, Australia and Southeast Asia, 22 June 2010, Singapore Health Promotion Board, Singapore.

Iyengar, S. (1991) Is Anyone Responsible? How Television Frames Political Issues. Chicago: University of Chicago Press.

Lee, S. and Basnyat, I. (2012) From Press Release to News: Mapping the Framing of the 2009 H1N1 A Influenza Pandemic. Health Communication, DOI:10.1080/10410236.2012.658550

http://dx.doi.org/10.1080/10410236.2012.658550

Lopes, F., Ruão, T., Marinho, S. and Araújo, R. (2012) Media pandemic: Influenza $\mathrm{A}$ in Portuguese newspapers. International Journal of Healthcare Management, 5, 1:19-27.

Matthes, J. (2009). What's in a frame? A content analysis of media-framing studies in the world's leading communication journals, 1990-2005. Journalism \& Mass Communication Quarterly, 86: 349-367.

Nerlich, B. and Koteyko, N. (2011) Crying wolf? Biosecurity and metacommunication in the context of the 2009 swine flu pandemic. Health \& Place doi:10.1016/j.healthplace.2011.02.008

doi:10.1016/j.healthplace.2011.02.008

Oh, H. J., Hove, T., Paek, H.J., Lee, B., Lee, H. and Song, S.K. (2012) Attention cycles and the H1N1 pandemic: A cross-national study of US and Korean newspaper coverage. Asian Journal of Communication, 22, 2: 214-232. 
Perri 6. (2005) What's in a frame? Social organization, risk perception and the sociology of knowledge. Journal of Risk Research, 8, 2: 91-118.

Reese, S. (2001) Prologue--Framing public life: A bridging model for media research. In Framing Public Life: Perspectives on Media and our Understanding of the Social World. S. Reese, O. Gandy and A. Grant (eds.), 7-31. Mahwah, N.J.: Lawrence Erlbaum.

Schudson, M. (2003) The Sociology of News. New York: Norton.

Semetko, H. and Valkenburg, P. (2000) Framing European politics: A content analysis of press and television news. Journal of Communication 50, 2: 93-109.

Stephenson, N. and Jamieson, M. (2009) Securitising health: Australian newspaper coverage of pandemic influenza. Sociology of Health \& Illness 31, 4: 525-539.

Strong, P. (1990), Epidemic psychology: A model. Sociology of Health and Illness, 12: 249-259.

Tannen, D. (1979) What's in a frame? Surface evidence for underlying expectations. In: Roy Freedle (ed). New Directions in Discourse Processing. Norwood, NJ: Ablex.

Tuchman, G. (1978) Making news: a study in the construction of reality. New York: Free Press.

Tversky, A. and Kahneman, D. (1981) The framing of decisions and the psychology of choice. Science, ns, 211, 4481: 453-458. 
Ungar, S. (2008) Global bird flu communication: Hot crisis and media reassurance. Science Communication, 29, 4: 472-497.

Vigso, O. (2010) Naming is framing: Swine flu, new flu, and A (H1N1). Observatorio (OBS*) Journal, 4, 3: 229-241.

Vreese, C.H. de (2005) News framing: Theory and typology. Information Design Journal and Document Design 13, 1: 51-62.

Wagner-Egger, P., Bangerter, A., Gilles, I., Green, E., Rigaud, D., Krings, F., Staerklé, C. and Clémence, A. (2011) Lay perceptions of collectives at the outbreak of the H1N1 epidemic: heroes, villains and victims. Public Understanding of Science, 20: 46-476.

Wang, W., Smith, R. and Worawongs, W. (2010) "Googling the H1N1 Flu: Investigating Media Frames in Online News Coverage of the Flu Pandemic" Paper presented at the annual meeting of the International Communication Association, Suntec Singapore International Convention \& Exhibition Centre, Suntec City, Singapore, Jun 22, 2010 http://www.allacademic.com/meta/p405189_index.htm1

WHO (2004) Best practices for communicating with the public during an outbreak. Report of the WHO Expert Consultation on Outbreak Communications, held in Singapore, 21-23 September 2004. 